\title{
ANÁLISE DO PERFIL DOS MESTRANDOS DO PROGRAMA DE PÓS GRADUAÇÃO AMBIENTE E SISTEMAS DE PRODUÇÃO AGRÍCOLA
}

\author{
MENDES, Inês Roeder Nogueira ${ }^{1}$ \\ ASCARI, João Paulo ${ }^{2}$ \\ BORGES, Janaína Domingos ${ }^{3}$ \\ TOLEDO, Martins ${ }^{4}$ \\ GALVANIN, Edinéia Aparecida dos Santos ${ }^{5}$
}

\begin{abstract}
RESUMO: No Brasil tem-se observado aumentos significativos nos cursos de Pós-Graduação, nesse contexto, foi aprovado no ano de 2010 o Programa de Pós-Graduação em Ambiente e Sistemas de Produção Agrícola na Universidade do Estado de Mato Grosso, Campus de Tangará da Serra. Com base nisso, o objetivo deste estudo foi fazer uma análise do perfil e produção cientifica dos mestrandos do Programa de Pós-Graduação em Ambiente e Sistemas de Produção Agrícola. Foi realizado a coleta de dados das turmas de 2011, 2012 e 2013, sendo coletadas via análise documental no Currículo Lattes e na página do PPGASP. Para análise dos dados nominais foram atribuídos valores numéricos, que permitiu aplicação da estatística quantitativa descritiva, enquanto que para as variáveis publicação total de artigos e publicação por gênero foi aplicada a estatística inferencial. No geral verificouse maior participação feminina, de acadêmicos que concluíram a graduação na UNEMAT, sendo formados na maioria, Bacharel em Agronomia e Ciências Biológicas. Grande parte dos ingressantes no mestrado são recémformados e as três áreas de concentração profissional dos egressos foram: serviços públicos, docência e doutorado. A produção de artigos não apresentou diferença significativa entre as turmas, entretanto, diferiu quanto ao Qualis do periódico, sendo que os NC, B3 e B1 foram mais representativos. Para publicação por gênero masculino e feminino não se observou diferença significativa. Com isso, verificou-se que o PPGASP proporciona condições para a continuidade da formação acadêmica para pesquisa e docência.
\end{abstract}

Palavras-chave: Pós-Graduação. Mestrado Acadêmico. PPGASP. Egressos.

SUMMARY: In Brazil has seen significant increases in the Graduate courses in this context was approved in 2010 the Programa de Pós-Graduação em Ambiente e Sistemas de Produção Agrícola (PPGASP) at the State University of Mato Grosso, Tangara da Serra of Campus Saw. An interdisciplinary program meets tickets from various areas of higher education. Based on this, the objective of this study was to make a descriptive profile analysis and scientific production of postgraduate students of the Programa de Pós-Graduação em Ambiente e Sistemas de Produção Agrícola. It conducted a census in the classes of 2011, 2012 and 2013, where the information was collected through documentary analysis in Lattes and PPGASP page, and analysis of the nominal data were assigned numerical values, which allowed the application of quantitative descriptive statistics. Overall there was a higher female participation of academics who have completed graduation in UNEMAT being formed mostly Bachelor in Agronomy and Life Sciences. Much of entering the Masters are newly formed and the three areas of professional concentration of the graduates were: public services, teaching and doctoral degrees. The class 2011 was greater scientific production of articles, and overall, there was a higher number of publications in journals with Qualis B3 and B1. Thus, it was found that the PPGASP provides conditions for the continuity of academic education to research and teaching.

Keyworks: Graduate. Academic Master. PPGASP. Graduates.

\footnotetext{
${ }^{1}$ Engenheira agrônoma e Mestranda em Ambiente e Sistemas de Produção Agrícola - UNEMAT.

${ }^{2}$ Engenheiro agrônomo e Mestrando em Ambiente e Sistemas de Produção Agrícola - UNEMAT.

${ }^{3}$ Bacharel em administração, docente no ensino superior e mestranda em Ambiente e Sistemas de Produção Agrícola - UNEMAT

${ }^{4}$ Bacharel em ciências contábeis, técnico de indigenismo e mestrando em Ambiente e Sistemas de Produção Agrícola - UNEMAT

${ }^{5}$ Professor Adjunto, docente permanente dos Programas de pós-graduação, Coordenadora dos projetos: PIBID, FAPEMAT, FINEP e Consultor ad hoc dos periódicos IEEE da Universidade do Estado de Mato Grosso
} 


\section{INTRODUCÃO}

Os cursos de Pós-graduação vêm crescendo no Brasil, isso demonstra a procura crescente por aperfeiçoamento profissional dos acadêmicos brasileiros. Porém essa jornada acadêmica se torna longa no país, sendo que o tempo para chegar ao nível de doutor pode demorar cerca de 11 anos, contando a partir da graduação. A Pós-Graduação oferece maiores vantagens para os profissionais que irão atuar nas áreas de pesquisa e docência, sendo menos atraente para profissionais de outros campos (VELLOSO, 2004).

Os cursos de Pós-Graduação nos anos 90 tinham como princípio a formação de profissionais com habilidades para realizar pesquisa e ingressar na área da docência. Como objetivos de formação, visavam o desenvolvimento do senso crítico do profissional, por esse motivo, os candidatos para a vaga necessitavam apresentar vocação ou muita facilidade para atuar nas áreas de pesquisa e docência. Os diversos Programas de Pós-Graduação de nível mestrado e doutorado estão presentes em diversas áreas do conhecimento, em que geralmente, os pós-graduandos devem cursar as disciplinas, cumprir todos os créditos, apresentar e defender seu projeto de pesquisa, por fim publicar artigos em periódicos relevantes (VELLOSO, 2004).

Em relação ao Programa de Pós-Graduação em Ambiente e Sistemas de Produção Agrícola (PPGASP), por ser um Programa de Mestrado Acadêmico interdisciplinar, permite a entrada de acadêmicos com formação em diversas áreas, formando um grupo misto de debate contribuindo para a formação.

O PPGASP visa formar profissionais com visões holísticas dos problemas e oportunidades, para que sejam capazes de elaborar projetos aplicáveis para a difusão de tecnologias nos sistemas de produção agrícola, na avaliação e conservação ambiental, dessa forma, buscar a sustentabilidade do Agroecossistema (BRASIL, 2010a).

A análise do perfil dos mestrandos pode auxiliar na avaliação do Programa, podendo observar se o público alvo está sendo atingido qual está sendo atraído para a pós-graduação. Outrossim também deve-se atentar a atuação profissional dos mestres formados no Programa, se estes estão atuando na área de formação ou continuando a sua formação acadêmica, sendo interessante também investigar a produção destes após o mestrado.

Em virtude disso, o objetivo deste estudo foi fazer uma análise descritiva do perfil e produção cientifica dos mestrandos do Programa de Pós-Graduação Ambiente e Sistema de Produção Agrícola.

\section{REFERENCIAL TEÓRICO}

\subsection{Programa de Pós-Graduação em Ambiente e Sistemas de Produção Agrícola}

O Programa de Pós-Graduação em Ambiente e Sistemas de Produção Agrícola (PPGASP) stricto sensu teve início em 24 de novembro de 2010, quando a execução do Programa a nível de mestrado foi aprovada e autorizada pela Universidade do Estado de Mato Grosso (UNEMAT) e pela CAPES, sendo vinculado ao Campus Universitário de Tangará da Serra - CUTS. (BRASIL, 2010a).

O PPGASP tem por objetivo atuar nas linhas de pesquisas voltadas a avaliação e conservação ambiental em consonância com aplicação de tecnologias nos sistemas de produção agrícola do Estado de Mato Grosso. Desse modo, elaborar ou adaptar metodologias, indicadores e modelos para serem aplicados na prática, visando a sustentabilidade dos sistemas de produção agrícola (BRASIL, 2010a).

O programa é interdisciplinar e conta com duas áreas de atuação, desenvolvidas para responder aos seus objetivos, sendo elas: Modelagem e indicadores socioambientais para sistemas agrícolas e conservação ambiental, e práticas de produção agrícola e conservação ambiental (BRASIL, 2010b). 
O corpo docente do PPGASP é constituído totalmente por doutores, que atuam de forma direta e continua junto ao Programa. Também atuam no mestrado professores colaboradores, que vem de outras instituições nacionais e/ou internacionais para contribuir com a execução das atividades acadêmicas e cientificas. Ao ser integrado ao Programa, o docente deve participar de projetos de pesquisa, ministrar aulas das disciplinas, participar de bancas e ainda publicar artigos em periódicos respeitados e com bom conceito perante ao sistema Qualis/CAPES (BRASIL, 2010b).

\subsection{Os Mestrandos do Programa de Pós-Graduação em Ambiente e Sistemas de Produção Agrícola}

A pós-graduação stricto sensu tem grande contribuição na carreira acadêmica e formação de profissionais, onde o PPGASP objetiva formar profissionais com uma visão holística em relação aos problemas e oportunidades. As instituições atuantes na área da pesquisa têm aumentado significativamente nos últimos anos, sendo que Spink (1997) relatou que no passado o mestrado era o nível de graduação mais alto e comum na comunidade cientifica, e atualmente as pesquisas são conduzidas na maioria por doutores, sendo o nível de formação desejado por quem ingressa na pós-graduação, pois o pesquisador necessita se aperfeiçoar cada vez mais, obter mais conhecimentos e ampliar seu campo de visão em relação ao mundo.

Dentro desse contexto de continuidade da formação acadêmica, Godarth et al., (2014) enfatizaram a importância do papel que as universidades estaduais desempenham na difusão do conhecimento técnico cientifico, os quais geram aplicações de projetos de pesquisa, ensino e extensão. Para que o sistema acadêmico funcione com eficiência, as turmas de egressos devem apresentar um perfil de Pós-graduandos focados na aplicação de suas pesquisas em função do desenvolvimento, solução de problemas e produção de conhecimentos para população.

Os interessados em concorrer a vaga no Programa podem ter formação em nível superior em qualquer área do conhecimento, essa característica dos candidatos responde a área de atuação interdisciplinar. Sendo que este visa atender as necessidades regionais e dar continuidade a formação dos acadêmicos da própria instituição (BRASIL, 2010b; BRASIL, 2011).

O mestrando compromete-se a desenvolver pesquisas de qualidade para publicação em periódicos conceituados. Desse modo, o egresso atende um dos requisitos do Programa, que é a publicação de artigos em revistas bem avaliadas na área interdisciplinar, que no Brasil são avaliadas pelo Qualis/CAPES (BRASIL, 2011).

\subsection{Coleta e análise de dados}

A comunidade acadêmica brasileira apresenta uma característica de ter um cadastro nacional de currículos, a Plataforma Lattes, onde se agrupam informações de pesquisas, publicações, orientações, entre outras. Pode ser considerada uma base de dados forte e confiável, apesar das dificuldades em trabalhar com esses dados (DIGIAMPIETRI et al., 2015).

Foi realizada a análise quantitativa descritiva dos resultados coletados via análise documental online. Conforme Gil (2007), pesquisas com objetivos descritivos visam revelar maiores informações de determinada população estudada. Esse tipo de pesquisa tende a sumarizar características básicas de uma população em estudo e apresentar de forma prática e fácil os resultados, sendo muito utilizado em pesquisas bibliométricas, levantamentos e outras pesquisas que utilizam dados secundários (CRESPO, 2002; SILVA; GOMIDE, 2011). 
A aplicação do presente estudo permite conhecer características do Programa de Pós-Graduação em Ambiente e Sistemas de Produção Agrícola, assim como representar o perfil dos seus egressos. Para Lakatos e Marconi (1991), as pesquisas quantitativas com objetivo descritivo irão revelar características da população, tendo por base investigações empíricas podendo ou não utilizar de análises estatísticas para compreender determinados fenômenos e fatos.

A estatística inferencial, também chamada indutiva, se difere da descritiva pois a partir dela se faz a análise e interpretação dos dados de maneira afirmativa, baseado na probabilidade, a partir das técnicas de estimação ou testes de hipóteses, e esses resultados podem ser generalizados para toda a população a partir da amostra (COSTA, 2012).

\section{METODOLOGIA}

A população em estudo constitui-se de todos os mestres formados pelo Programa de Pós de Graduação Ambiente e Sistemas de Produção Agrícola (PPGASP) nas três primeiras turmas (2011, 2012 e 2013), sendo 12 mestrandos na primeira turma, 11 na segunda e 16 na terceira, totalizando 39 mestres.

Para a realização deste estudo os dados foram coletados por meio da análise documental (GIL, 2007), sendo realizado um levantamento via internet, o que os caracteriza como sendo de natureza secundaria (RICHARDSON, 2008). O banco de dados foi a página do PPGASP ${ }^{6}$ () e do Currículo Lattes $^{7}$, esse método de coleta também foi utilizado por Barbosa et al. (2009), que também fez buscas no Currículo Lattes da população considerada em seu estudo. Foi realizada uma análise individual dos currículos, para evitar falhas como desatualização e repetição de informações, e os dados foram tabulados em planilhas para posterior análise e aplicação de testes.

No levantamento foram considerados dados de natureza nominal (gênero do mestrando, formação na graduação, instituição da graduação, área de formação do orientador, área de atuação profissional dos egressos e a qualidade das publicações de artigos), e dados numéricos (tempo entre a saída da graduação e entrada no mestrado, quantidade de publicação total e por gênero).

Para os dados de natureza nominal foram atribuídas categorias numéricas (frequência relativa e absoluta), os quais então foram analisados a partir da estatística descritiva com abordagem quantitativa. Conforme Martins e Theóphilo (2007), esse tipo de abordagem deve apresentar dados numéricos organizados, sumarizados, caracterizados e interpretados conforme o método empregado na coleta.

Para a variável tempo entre graduação e mestrado foi realizada a tabela de frequência relativa e os resultados plotado em Figura. Referente a variável artigos publicados foram contabilizados apenas os artigos publicados a partir da data de ingresso no mestrado e aqueles em que o mestrando foi autor. Para a variável qualidade dos artigos, pesquisou-se o Qualis (2014) dos periódicos que foram publicados, pelo acesso a Plataforma Sucupira ${ }^{8}$.

Para a análise das variáveis gênero do mestrando, formação na graduação, instituição da graduação, área de formação do orientador, área de atuação dos egressos e tempo entre a saída da graduação e entrada no mestrado foi utilizada a estatística descritiva.

Nas variáveis quantidade de artigos total e por gênero, foi aplicada a estatística inferencial paramétrica e não paramétrica, onde inicialmente foi realizado o teste de normalidade dos dados com o teste de Shapiro-Wilk, utilizando o software estatístico R e o pacote stats. Nos dados que apresentaram distribuição normal foi aplicado o teste F, em seguida o teste $t$ de Student por meio do programa Excel.

\footnotetext{
${ }^{6} \mathrm{http}: / /$ portal.unemat.br/ppgasp

${ }^{7}$ http://buscatextual.cnpq.br/buscatextual/busca.do?metodo=apresentar

${ }^{8}$ https://sucupira.capes.gov.br/sucupira/public/consultas/coleta/veiculoPublicacaoQualis/listaConsultaGeralPeriodico $\underline{\text { s.jsf }}$
}

Nucleus,v.14,n.1,abr.2017 
Para os dados não normais, realizou-se o teste de associação não paramétrico Kruskal-Wallis $(\mathrm{p} \leq 0,05)$ utilizando o software estatístico R e o pacote stats (R CORE TEAM, 2016).

\section{ANÁLISE DOS RESULTADOS}

Os resultados obtidos a partir da análise descritiva dos dados estão representados em figura e tabelas que evidenciam a grande diversidade dos ingressos e egressos no PPGASP. Dos 39 currículos analisados apenas dois estavam desatualizados. Essa dificuldade em se trabalhar com a base de dados da plataforma Lattes também foi verificada por Digiampietri et al. (2015), ressaltando que os dados dos currículos são preenchidos manualmente e o acesso a dados mais elaborados nem sempre é permitido pela CAPES.

Percebeu-se uma grande variação de gêneros entre as turmas (Figura 1), demonstrando a participação e interesse de homens e mulheres pela continuidade da formação acadêmica.

Figura 1 - Relação percentual (\%) do gênero masculino e feminino dos mestres formadas nas turmas de 2011, 2012 e 2013 do Programa de Pós-Graduação em Ambiente e Sistemas de Produção Agrícola PPGASP, UNEMAT.

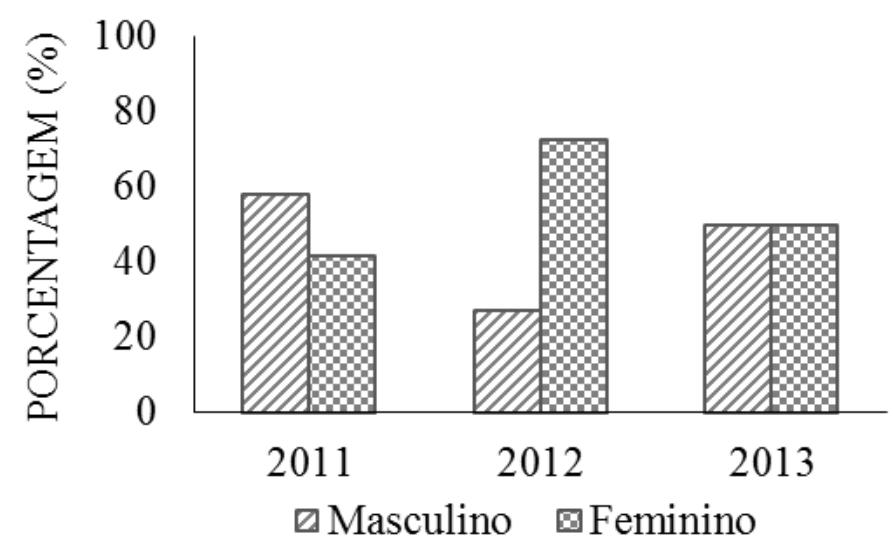

Fonte: Dados coletados pelos autores a partir do Curriculum Lattes dos mestres.

Observa-se que em 2011, a participação masculina foi 16,66\% maior que a participação do sexo feminino e, no ano subsequente houve uma inversão substancial em 45,46\%, já em 2013 a participação de homens e mulheres foi idêntica, na média das três turmas ocorreu uma maior participação do gênero feminino.

Em uma análise de duas turmas nos anos de 2013 e 2014, Godarth et al. (2014) encontra predominância de mulheres no Programa de Mestrado em Gestão de Desenvolvimento Regional da UNIOESTE - PR. A maior procura das pessoas do sexo masculino por cursos de Pós-Graduação foi constatada por Barbosa et al. (2009) em levantamento semelhante, porém, num espaço temporal de 10 anos e em um mestrado em Medicina (Radiologia). Mendes (2010) no estudo dos egressos do Programa de mestrado em Ciências e Saúde da Universidade Federal do Piauí encontra o resultado onde, predomina o sexo feminino. Todos esses resultados corroboram com os obtidos nesse estudo, e dependendo da área de estudo ocorre predominância de um ou outro gênero, porém apenas com três turmas não se pode tirar conclusões definitivas e generalizar para todas as turmas.

Para se explicar a predominância feminina no mestrado seria necessário analisar outros parâmetros como as oportunidades locais e oferta de cursos de graduação, onde poderia se trabalhar uma pesquisa qualitativa. 
O intervalo de tempo entre a saída da graduação e a entrada no mestrado (Figura 2) foi classificado em 6 classes conforme a frequência relativa calculada, e variou de 1 a 12 anos, sendo o valor 1 - ingressos formados a menos de um ano na graduação.

Figura 2 - Tempo (em anos) entre a saída da graduação e ingresso dos mestrandos das turmas de 2011, 2012 e 2013 do Programa de Pós-Graduação em Ambiente e Sistemas de Produção Agrícola - PPGASP, UNEMAT.

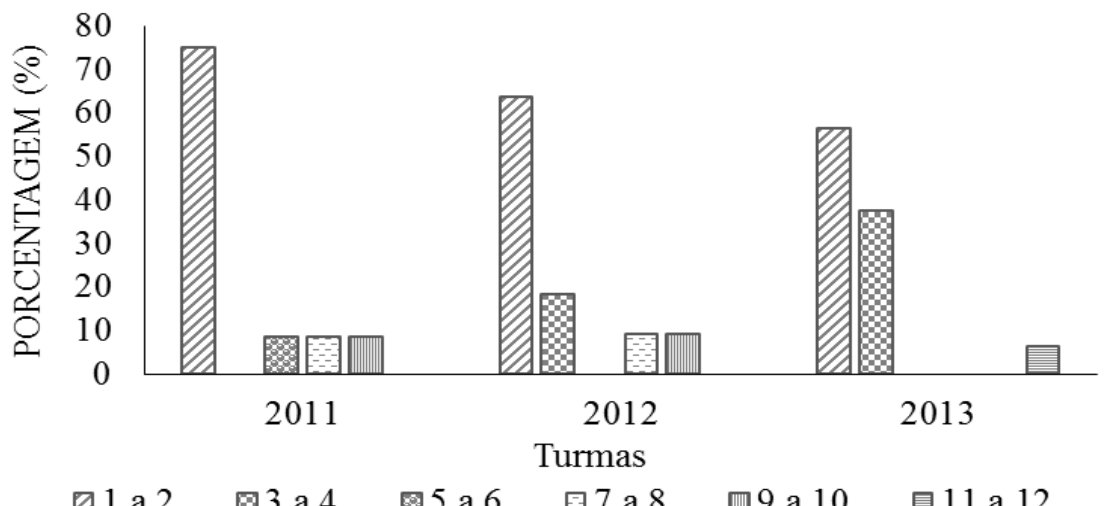

Fonte: Dados coletados pelos autores a partir do Curriculum Lattes dos mestres.

Em todas as turmas observou-se a predominância de ingressantes recém-formados no $3^{\circ}$ grau, entre 1 a 2 anos após conclusão. De um total de 39 mestrandos 25 ingressaram no mestrado em até dois anos após a conclusão da graduação.

A outra série que se destacou foi a de ingressantes entre 3 a 4 anos de formados nas turmas de 2012 e 2013. As demais séries apresentadas nas 3 turmas foram de poucos mestrandos ou até mesmo inexistentes como demonstra a figura.

Os formandos que estão a mais tempo distantes da academia não aparecem expressivamente no Programa, já os formandos com menos de 4 anos são maioria nas 3 turmas pesquisadas, demonstrando que quanto maior o tempo decorrido do termino da graduação mais difícil se torna para o egresso retornar a vida acadêmica. Alguns autores (HOLLEY; CALDWELL, 2012; TOBBELL; O’DONNELL, 2013) relatam vários fatores para a evasão dos acadêmicos dos cursos e a não entrada na pós-graduação, para tanto deveria ser avaliada qualitativamente essa opção dos acadêmicos em ingressar brevemente ou não no mestrado.

Este resultado (Figura 2) pode ser visto como parte do processo de desenvolvimento da Instituição de Ensino Superior - IES e do país quanto aos incentivos a pesquisa e ensino superior, o apoio vindo do governo junto as IES e o tempo necessário para aperfeiçoar o seu desenvolvimento impactam nos resultados do Programa.

Quanto ao desenvolvimento profissional do ingressante stricto sensu, voltado principalmente para profissionais na área de pesquisa e ensino é relevante se atentar ao propósito a longo prazo por ele almejado ao ser selecionado, identificar porque quer fazer, qual suas aspirações, qual o sentido do mestrado na vida do candidato, esta seleção para entrada dos formandos no Programa também influenciam os resultados esperados pelo mesmo a longo prazo, corroborando com os autores, Velloso (2014) expõem sobre a pós-graduação quanto oferecer incentivos para captar profissionais que estejam atuando na pesquisa e docência.

Quanto aos egressos da graduação e/ou licenciatura que participaram do mestrado, observou-se egressos de outras instituições, uma média de $13 \%$ enquanto que da UNEMAT são $87 \%$ (Figura 3). Tais informações demonstram que a instituição UNEMAT oferece condições para a continuidade da formação acadêmica de seus alunos. 
Figura 3 - Instituições de formação dos mestrandos ingressos das turmas de 2011, 2012 e 2013 do Programa de Pós-Graduação em Ambiente e Sistema de Produção Agrícola - PPGASP, UNEMAT.

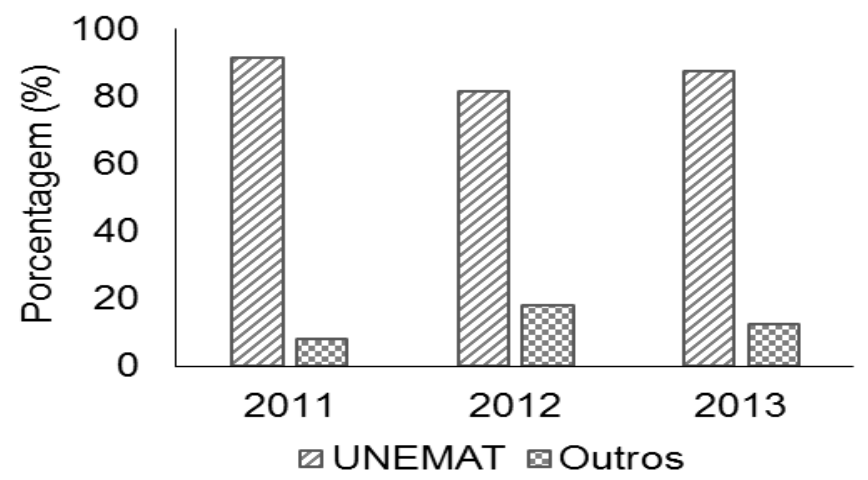

Fonte: Dados coletados pelos autores a partir do Curriculum Lattes dos mestres.

Na Universidade Federal do Rio de Janeiro há uma inversão, onde 72,34\% dos mestres e doutores vieram de outras instituições (BARBOSA et al., 2009) e, no Recife, feito um estudo da origem geográfica dos mestrandos entre os anos de 2005 e 2009, houve uma predominância de ingressos oriundos da cidade de Recife, contudo, os ingressos do interior foram representativos, entretanto, no estudo não foi levantado as instituições de graduação. No Paraná, a predominância de ingressos em dois anos de estudo (2013 e 2014), foi da cidade onde o Programa funciona (GODARTH et al., 2014).

Um dos fundamentos da proposta do Programa de mestrado foi a possibilidade de oferecer uma continuação da formação dos acadêmicos da própria instituição, além de atender o Estado de Mato Grosso, que é carente em cursos de pós-graduação, o autor Gotdarth et al. (2014) defende a ideia de continuidade da formação acadêmica. Sendo que no campus em que está situado o PPGASP são ofertados dois cursos de graduação que estão diretamente ligados as linhas de pesquisa do Programa, sendo que os acadêmicos formados nestes cursos tiveram maior predominância no ingresso no mestrado (Figura 4).

Figura 4 - Áreas de formação a nível de graduação dos mestrandos das turmas de 2011, 2012 e 2013 do Programa de Pós-Graduação em Ambiente e Sistemas de Produção Agrícola - PPGASP, UNEMAT.

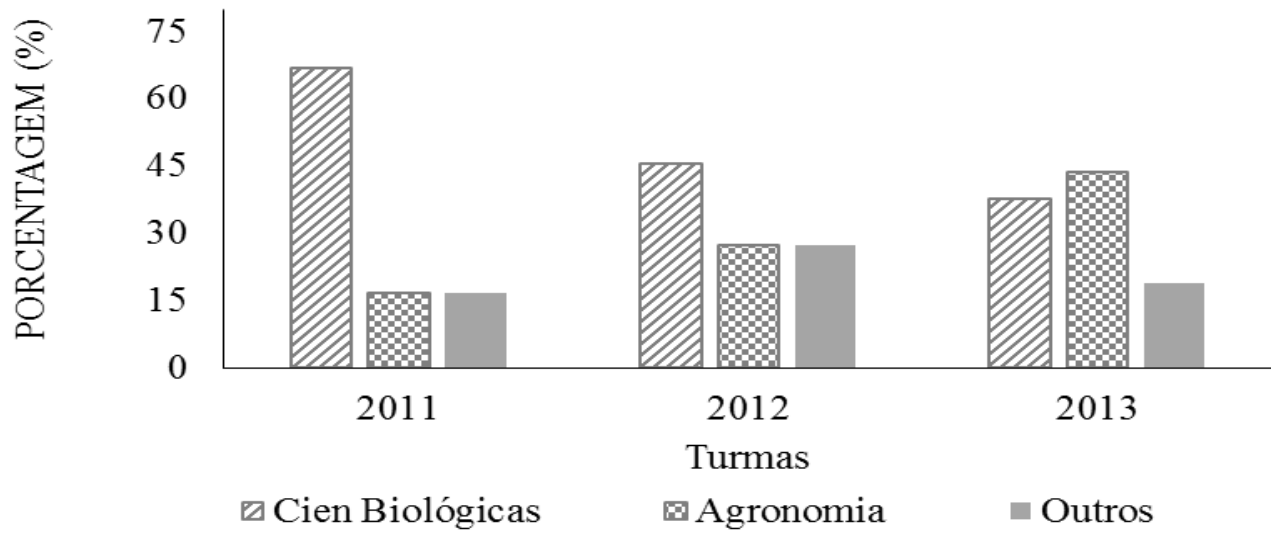

Fonte: Dados coletados pelos autores a partir do Curriculum Lattes dos mestres.

A formação dos ingressos na turma de 2011 e 2012 se destaca na área de ciências biológicas, com o maior número de mestrandos, e na turma de 2013 a área de agronomia alcançou 43,75\% da turma, e a área de ciências biológicas chegou a 37,50\%. Foram classificados como "outros" cursos que tiveram menor representação, sendo no máximo 3 por turma, considerando os cursos de administração, contabilidade, licenciaturas, turismo, engenharias agrícola e florestal. Estes cursos se equiparam com a agronomia, representando $16,67 \%$ na turma de 2011, e 27,27 \% na turma de 2012.

Pode-se perceber uma evolução no interesse de acadêmicos de diversas áreas pelo mestrado 
interdisciplinar, sendo a turma de 2013 considerada a mais heterogenia favorecendo a dinâmica da visão interdisciplinar proposta pelo Programa.

A formação dos ingressos não é considerada na escolha do orientador, podendo este ser de área diferente, provocando uma maior troca de experiências para ampliar os conhecimentos de ambos. Esse é um dos objetivos de um Programa interdisciplinar, nesse âmbito o PPGASP vem conseguindo essa interação entre áreas (Figura 5).

Figura 5. Porcentagem $(\%)$ das diferenças entre as áreas de formação dos orientadores e mestrandos das turmas de 2011, 2012 e 2013 do Programa de Pós-Graduação em Ambiente e Sistemas de Produção Agrícola - PPGASP, UNEMAT.

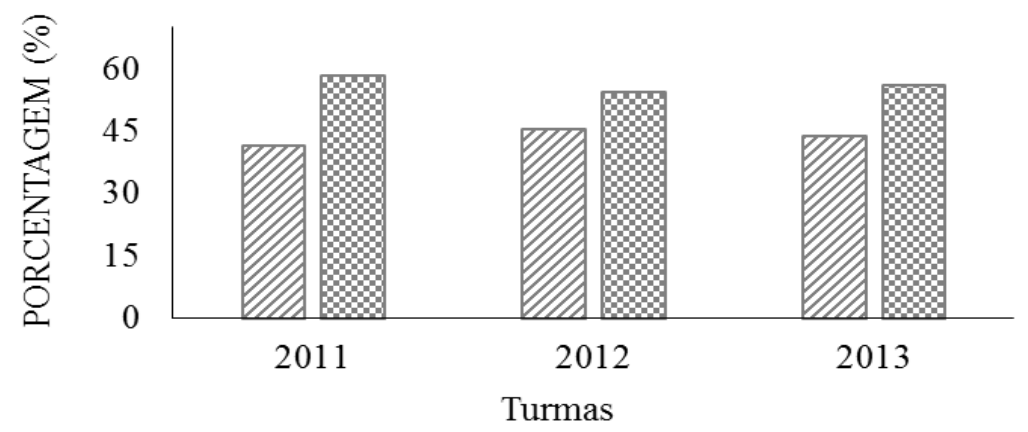

$\square$ Área igual $\quad$ Área diferente

Fonte: Dados coletados pelos autores a partir do Curriculum Lattes dos mestres e orientadores.

Nas três turmas, as orientações dos mestrandos em sua maioria foram realizadas por orientadores de áreas diferentes, com a seguinte porcentagem: 2011 com 58,33\%; 2012 com 54,55\% e a turma de 2013 com $56,25 \%$. Entretanto não houve diferença expressiva com a orientação por professores da mesma área.

Este resultado traz consigo uma posição de cautela para o Programa, visto o seu processo de construção em um formato interdisciplinar, questionando o que moveria mais rápido os docentes a se deslocarem da disciplina para uma dinâmica interdisciplinar junto a seus orientandos.

A investigação da área de atuação dos egressos pode contribuir para o Programa avaliar o cumprimento dos seus objetivos na formação de mestres. Também pode revelar que áreas os mestres estão atuando mais fortemente, e se estão continuando a sua formação acadêmica. E na Figura 6 podemos observar que as três principais áreas de atuação dos egressos são a docência na UNEMAT e em outras IES, também a preferência pelo doutorado.

Figura 6 - Porcentagem (\%) das áreas de atuação profissional dos egressos das turmas de 2011, 2012 e 2013 do Programa de Pós-Graduação em Ambiente e Sistemas de Produção Agrícola - PPGASP, UNEMAT.

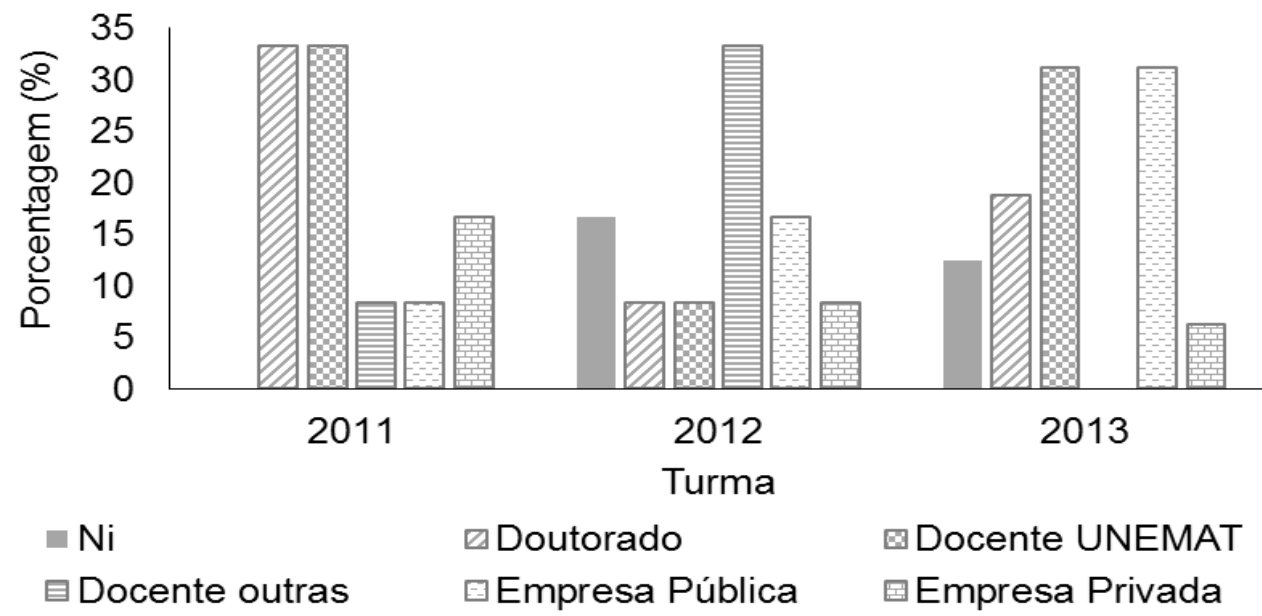

Fonte: Dados coletados pelos autores a partir do Curriculum Lattes dos mestres. 
Não houve uma constância de uma área de atuação entre as turmas de egressos, entretanto, observou-se a predominância de algumas áreas em cada turma, sendo que na primeira turma prevaleceu a atuação como docente da UNEMAT e o ingresso no doutorado, na segunda os egressos foram para a área da docência em outras instituições de ensino e na terceira turma foi observado que os mestres optaram pela docência na UNEMAT e cargos públicos.

A docência na UNEMAT teve maior destaque nas turmas de 2011 e 2013, e ocorreu também de nas turmas de 2012 e 2013 cerca de $17 \%$ e 13\%, respectivamente, não informarem (NI) em seus currículos a atual área de atuação profissional.

Os profissionais empresa pública aparecem de forma crescente já os da empresa privada aparecem de forma decrescente nas turmas. É interessante investigar o motivo para o resultado do crescente interesse dos profissionais por atuar em empresas públicas, verificar se vão agregar ao Programa os resultados esperados para pesquisa e ensino. Conforme Barth et al. (2016) os mestres formados recebem uma maior remuneração quando atuam em carreiras públicas que ofereçam plano de carreira e quando atuam na docência, esse aumento de renda é ainda mais favorável para aqueles que concluem um doutorado.

Conforme observado por Braga et al. (2014) em um levantamento na pós-graduação em fonoaudiologia, as produções acadêmicas são publicadas preferencialmente em forma de artigos e em revistas brasileiras conceituadas. Esse padrão também é observado no PPGASP, sendo que o modelo de dissertação já está em formato de artigos.

Os resultados do teste de normalidade mostraram que os dados de publicação total de artigos não tiveram distribuição não normal, por outro lado, constatou-se a normalidade para os dados de publicação por gênero (Tabela1).

Tabela 1 - Teste de Normalidade de Shapiro-Wilk (W) das variáveis Publicação de artigos e Publicação por gênero.

\begin{tabular}{lcll}
\hline Variável & W (Valor do teste) & p-valor & \multicolumn{1}{c}{ Conclusão* } \\
\hline Publicação de Artigos & 0,75333 & $5,573 \mathrm{e}^{-05}$ & $\mathrm{p} \leq 0,05=$ rejeita $\mathrm{H}_{0}$, aceita $\mathrm{H}_{1}$ \\
Publicação por Gênero & 0,83671 & 0,1224 & $\mathrm{p} \geq 0,05=$ aceita $\mathrm{H}_{0}$ \\
\hline
\end{tabular}

${ }^{*} \mathrm{H}_{0}$ : os dados são iguais e seguem uma distribuição normal, $\mathrm{H}_{1}$ : os são diferentes e não seguem uma distribuição normal.

Fonte: Elaborado pelos autores do artigo (2016).

Observou-se que ocorreu diferença significativa entre a quantidade de artigos nos diferentes Qualis, porém, não ocorreu diferença significativa entre as turmas (Tabela 2). Percebeu-se uma maior quantidade de artigos publicados em revistas não classificadas na área interdisciplinar (NC), assim como em revistas de Qualis B3 e B1.

Tabela 2 - Publicações de artigos nas turmas de 2011, 2012 e 2013 do Programa de Pós-Graduação em Ambiente e Sistemas de Produção Agrícola - PPGASP, UNEMAT.

\begin{tabular}{|c|c|c|c|c|c|c|c|c|c|c|}
\hline \multirow{2}{*}{ Turma $^{2}$} & \multicolumn{8}{|c|}{ Qualis 2014 ${ }^{1 *}$} & \multirow[b]{2}{*}{ Total } & \multirow[b]{2}{*}{ Média } \\
\hline & A1 & A2 & B1 & B2 & B3 & B4 & B5 & $\mathbf{N C * *}$ & & \\
\hline 2011 & 1 & 1 & 6 & 2 & 13 & 0 & 1 & 12 & 36 & 3,00 \\
\hline 2012 & 0 & 1 & 4 & 5 & 3 & 0 & 0 & 4 & 17 & 1,50 \\
\hline 2013 & 0 & 1 & 4 & 0 & 3 & 2 & 0 & 12 & 22 & 1,40 \\
\hline Total & 1 & 3 & 14 & 7 & 19 & 2 & 1 & 28 & 75 & 2,08 \\
\hline
\end{tabular}

${ }^{1}$ Difere estatisticamente pelo teste de Kruskal-Wallis $(\mathrm{p}=0.0193) .{ }^{2}$ Não difere estatisticamente pelo teste de KruskalWallis $(\mathrm{p}=0,6439)$ * Qualis interdisciplinar (2014) obtido através da plataforma sucupira. **Não classificado de acordo com o Qualis 2014 na área interdisciplinar.

Fonte: Elaborado pelos autores do artigo (2016). 
Podemos perceber que foram publicados muitos artigos em revistas sem Qualis interdisciplinar, entretanto é importante relatar que muitos periódicos não foram classificados na área interdisciplinar no ano de 2014, como o periódico cadernos de agroecologia, onde muitos mestrandos do Programa publicaram seus artigos. Também foi observado muitas publicações em revistas bem qualificadas na área especifica de formação, que muitas vezes não tem avaliação como interdisciplinar.

Do total de artigos, 45,33\% são derivados das dissertações defendidas no Programa, sendo que a primeira turma (2011) publicou mais artigos, no total e na média, com média de 3 artigos por mestrando. Nas turmas de 2012 e 2013 foram observadas medias de 1,5 e 1,4 artigos por mestrando, respectivamente. Esse decréscimo pode ter relação com a demora e a dificuldade de se publicar um artigo no Brasil, visto que muitos artigos destas turmas estão em tramite de publicação.

A pouca publicação de artigos em revistas com Qualis "A" pode ser devido a essa dificuldade e também ao elevado custo de publicação em periódicos com essa classificação. Ainda no final da década de 90 Mueller (1999) relatou essas dificuldades, enfatizando que no Brasil há uma demora nas publicações além do alto custo para publicar pesquisas cientificas, e que no país não há incentivos a publicações em periódicos de qualidade.

A produção de artigos também foi considerada por gênero, para esta variável aplicou-se o teste F, constatada a variância igual, foi realizado o teste $t$ de Student para variâncias equivalentes. Com os resultados pode-se inferir que a publicação não difere estatisticamente entre homens e mulheres.

Figura 7. Publicação por gênero das turmas do Programa de Pós-Graduação em Ambiente e Sistemas de Produção Agrícola - PPGASP, UNEMAT.

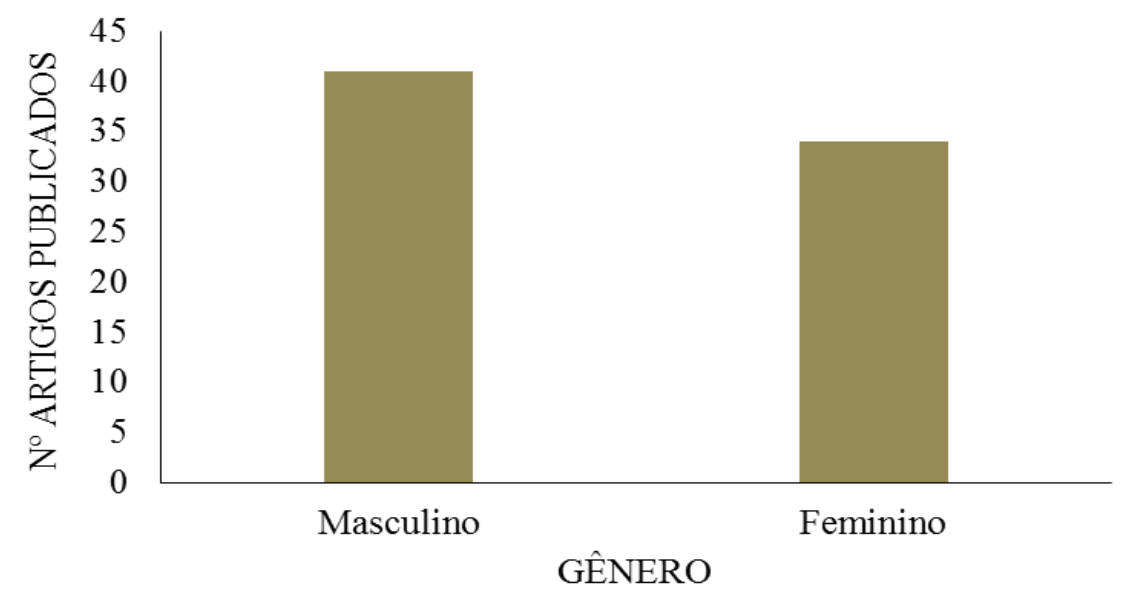

Fonte: Dados coletados pelos autores a partir do Curriculum Lattes dos mestres.

Alguns autores defendem o aumento da participação das mulheres no campo das ciências, especialmente na produção cientifica (LOPES, 2003; LETA, 2003) sendo que na literatura em diversas áreas foram encontrados maior publicação de autores do gênero masculino (LEITE FILHO, 2008; MENDES et al., 2010; BARBOSA; BARROS, 2011). Nesse estudo os dois gêneros não diferiram estatisticamente, demonstrando que existe uma tendência de maior participação feminina nas publicações.

Com isso, estudos como este são importantes para mostrar qual o perfil dos mestrandos do PPGASP, além de ser utilizado para o planejamento do programa quanto ao cumprimento de seus objetivos e diretrizes, como também auxiliar na opção de escolha em ingressar no respectivo curso de PósGraduação, além deste assunto se tornar tema de novas pesquisas. 


\section{CONSIDERAÇÕES FINAIS}

Os resultados desse estudo vêm colaborar com o Programa, de forma que apresenta o perfil dos ingressantes (antes, durante e depois), caracterizando-se como insumo para melhoria continua do programa, sendo fundamental tratar de maneira impessoal as tomadas de decisões, para geração dos resultados em conjunto com toda a equipe de trabalho. Em se tratando de um mestrado "novo", novas pesquisas devem ser realizadas à medida que forem formando mais turmas.

O Programa tem atingido seus objetivos na formação dos egressos e contribuído para a comunidade cientifica com as publicações de artigos. O PPGASP tem proporcionado condições para a continuidade da formação acadêmica para pesquisa e docência.

\section{REFERÊNCIAS}

BARBOSA, G.C.; BARROS, F.O. Perfil dos autores na produção científica em contabilidade: o caso do congresso USP de controladoria e contabilidade e do congresso ANPCONT. Enfoque: reflexão contábil, v. 29, n. 3, p. 22-33, 2011.

BARBOSA, S.F.F.; SASSO, G.T.M.D.; BERNS, I. Enfermagem e tecnologia: análise dos grupos de pesquisa cadastrados na Plataforma Lattes do CNPq. Texto Contexto Enfermagem, Florianópolis, v. 18, n. 3, p. 443-448, 2009.

BARTH, T.G.; ENSSLIN, S.R.; BORGERT, A. Os Benefícios Pessoais da Pós-Graduação Stricto Sensu: uma Análise na Percepção de Mestres em Contabilidade. Revista de Educação e Pesquisa em

Contabilidade, Brasília, v.10, n. 1, p. 106-128, 2016.

BRAGA, M.E.R. CHIARI, B.M. GOULART, B.N.G. Produção bibliográfica em artigos, livros e capítulos de livros de um programa de pós-graduação em fonoaudiologia: análise de indicadores bibliométricos.

Distúrbios da Comunicação, São Paulo, v.26, n.1, p.118-130, 2014.

BRASIL. RESOLUÇÃO No 080/2011 - Ad Referendum do CONEPE. Aprova o Regimento do Programa de Pós-graduação Stricto Sensu em Ambiente e Sistemas de Produção Agrícola, da UNEMAT. Cáceres: UNEMAT, 2011. 8p.

BRASIL. RESOLUÇÃO No 1 26/2010 - AD REFERENDUM DO CONEPE. Aprova o Regimento do Programa de Pós-graduação "Stricto Sensu” em Ambiente e Sistemas de Produção Agrícola, da UNEMAT. Cáceres: UNEMAT, 2010b. 19p.

BRASIL. RESOLUÇÃO No 125/2010 - AD REFERENDUM DO CONEPE. Aprova e autoriza a execução do Programa de Pós-graduação Stricto Sensu em Ambiente e Sistemas de Produção Agrícola vinculado a Pró-Reitoria de Pesquisa e Pós-graduação da Universidade do Estado de Mato Grosso. Cáceres: UNEMAT, 2010a. 3p.

CALLIYERIS, V.E.; CASAS, A.L.L. A utilização do método de coleta de dados via internet na percepção dos executivos dos institutos de pesquisa de mercado atuantes no Brasil. Interações (Campo Grande), Campo Grande, v. 13, n. 1, p. 11-22, 2012.

COSTA, G.G.O. Curso de Estatística Inferencial e Probabilidades - Teoria e Prática. $1^{\text {a }}$ ed. São Paulo: Atlas, 2012.p. 370.

CRESPO, Antônio Arnold. Estatística fácil. 17. ed. São Paulo: Saraiva, 2002.

DIGIAMPIETRI, L.A. Extração, caracterização e análises de dados de currículos lattes. Revista Eletrônica de Sistemas de Informação, v. 14, n. 2, p. 1-24. 2015. 
GIL, A.C. Como elaborar projetos de pesquisa. $4^{a}$ ed. São Paulo: Atlas, 2007.

GODARTH, K.A.L. et al. Análise dos Perfis das Turmas de 2013 e 2014 do Programa de Mestrado em Gestão e Desenvolvimento Regional da UNIOESTE Campus Francisco Beltrão. In: SIMPÓSIO DE EXCELÊNCIA EM GESTÃO E TECNOLOGIA, 11., 2014. Rio de Janeiro. Anais... SEGeT, Rio de Janeiro, 2014.

HOLLEY, K.A.; CALDWELL, M. L. The Challenges of Designing and Implementing a Doctoral Student Mentoring Program. Innovative Higher Education, v. 37, p. 243-253, 2012.

LAKATOS, E.M.; MARCONI, M.A. Fundamentos de metodologia científica. $5^{\text {a }}$ ed. São Paulo: Atlas, 2003. 310p.

LEITE FILHO, G.A. Padrões de Produtividade de Autores em Periódicos e Congressos na Área de Contabilidade no Brasil: um Estudo Bibliométrico. RAC. Revista de Administração Contemporânea, v. 12, p. 490-517, 2008.

LEITE FILHO, G.A. Perfil da produção científica dos docentes e programas de pós-graduação em ciências contábeis do Brasil. Revista de Contabilidade e Controladoria, Curitiba, v. 2, n. 2, p. 1-13, 2010.

LETA, J. As mulheres na ciência brasileira: crescimento, contrastes e um perfil de sucesso. Estudos Avançados, São Paulo, vol. 17 n. 49, 2003.

LOPES, M.M. Gênero e ciências no país: exceções à regra? ComCiência, Brasília, v. 1, n. 50, 2003.

MARTINS, G.A.; THEÓPHILO, C.R. Metodologia da investigação científica para ciências sociais aplicadas. $2^{\mathrm{a}}$ ed. São Paulo: Atlas, 2007. p. 250.

MENDES, P.H.C., et al. Perfil dos pesquisadores bolsistas de produtividade científica em medicina no CNPq, Brasil. Revista brasileira de educação em medicina. Rio de Janeiro, v. 34, n. 4, p. 535-541, 2010.

MUELLER, S.P.M. O círculo vicioso que prende os periódicos nacionais. DataGramaZero - Revista de Ciência da Informação, v. 2, n. 0, 1999.

R CORE TEAM. R: A language and environment for statistical computing. R Foundation for Statistical Computing, Vienna, Austria. 2016.

RICHARDSON, R. Pesquisa Social: métodos e técnicas. 3. ed. São Paulo: Atlas, 2008.

SILVA, P.A.; GOMIDE, F.V. Otimização do refeitório de uma mineradora para o controle e distribuição dos horários de almoço. Iberoamerican Journal of Industrial Engineering, v. 3, n. 1, p. 169-183, 2011.

SPINK, P. Formação acadêmica e a ciência: Ampliando o debate sobre o mestrado profissional. RAC.

Revista de Administração Contemporânea, v. 1, n. 3. p. 163-169, 1997.

TOBBELL, J.; O'DONNELL, V. L. Transition to postgraduate study: postgraduate ecological systems and identity. Cambridge Journal of Education, v. 43, n. 1, p. 123-138, 2013.

VELLOSO, J. A pós-graduação no Brasil: formação e trabalho de mestres e doutores no país. Cadernos de Pesquisa, São Paulo, v. 34, n. 122, p. 517, 2004. 